\title{
The living kidney donation process: role of the interdisciplinary team
}

\author{
Yin Hui (Meds 2015), Kyle Pangka (Meds 2016), and Alexander Yan (Meds 2015) \\ Faculty Reviewer: Dr. Faisal Rehman, MD, FRCPC, M.Ed (Department of Medicine, Division of Nephrology)
}

\section{INTRODUCTION}

End stage renal disease (ESRD) is becoming an increasingly prevalent illness in Canada. ${ }^{1}$ The Canadian Organ Replacement Register Annual Report released by the Canadian Institute for Health Information (CIHI) stated that the number of Canadians living with ESRD has tripled from 1990 to $2009 .{ }^{1}$ Unfortunately, the number of kidneys donated has not kept pace with this increase in demand. In 2009, approximately 38,000 Canadians are living with ESRD, with $59 \%$ on dialysis, and 3,000 patients on the transplant wait list. ${ }^{1}$ The increase in dialysis treatment also comes with a substantial cost to the health care system - the estimated cost for hemodialysis is $\$ 60,000$ per patient, per year. ${ }^{1}$ The CIHI estimates that a renal transplant saves the health care system $\$ 250,000$ per patient over a five-year period. ${ }^{1}$

Due to the shortage of cadaveric kidneys, there has been an increase in using donations from living donors, often from an offspring, parent, or other genetically related family members. Donations from unrelated donors also make up $30 \%$ of the donation pool, with a portion being strangers to the recipient. Several studies have shown that patients receiving living kidney donations from either genetically related and unrelated donors achieve better outcomes than patients receiving a kidney transplant from cadaveric donors. ${ }^{3,45}$ Living-donor transplantations have been shown to be associated with a shorter time to transplantation, and results in a better long-term graft and patient survival. ${ }^{6}$ As a result of the increasing importance of living donation, protocols have been developed to accommodate living donations: Live-Donor Paired Exchange, Live-Donor/Deceased-Donor Exchange, and Altruistic Living Nondirected Exchange. ${ }^{2}$ In the Live-Donor Paired Exchange, a donor-recipient pair (the patient requiring a transplant, and a willing donor who cannot provide a matching kidney) is matched with another donor-recipient pair such that a compatible donor-recipient exchange is made. This matching process, or chain, is continued until all recipients receive a kidney. In the Live-donor/Deceased-donor exchange, a donor-recipient pair is reassigned such that the live-donor is matched with a recipient already waiting on the deceased donor list. In exchange, the first recipient is moved nearer to the top of the cadaver list. Finally, the Altruistic Living Nondirected Exchange is true to its name - the kidney donation comes from a generous person who is a stranger to the recipient.

To provide sufficient care for both the donor and recipient, a large multidisciplinary team is required to address different facets of care, including processes of donation, matching, and maintenance of care. This article will discuss the living kidney donation process, as well as the role and importance of the multidisciplinary team.

\section{THE MATCHING PROCESS}

The Living Donor Paired Exchange is a program run through the Canadian Blood Services that identifies matches between potential living kidney donors and transplant recipients in Canada. ${ }^{7}$ Matching refers to the tests carried out by clinical scientists prior to transplantation to minimize the risks of acute or delayed graft rejection. This involves ensuring the blood type of the donor and recipient are compatible, testing the histocompatibility of the donor kidney, and screening the plasma of the recipient for antibodies against donor kidney cells. ${ }^{8}$ To test for histocompatibility the surface molecules present on the donor and recipient cells, specifically human leukocyte antigen (HLA) complexes, are compared and assessed for similarity. ${ }^{9}$ Higher similarity between donor and recipient HLA complexes are associated with increased long term survival rates, and a decreased chance that the immune system of the recipient will identify the donor cells as foreign. ${ }^{9}$ Individuals may have antibodies against HLA complexes circulating in their blood due to past transplants, pregnancies, or blood transfusions where their immune system was exposed to foreign human cells. ${ }^{10}$ This is why the plasma of recipients must be screened for antibodies targeting donor cells prior to transplantation in a process known as cross matching. ${ }^{10}$

\section{THE LIVING KIDNEY DONATION PROCESS}

In this section we will focus on several components of the organ donation process including assessment of the living donor, informed consent, and follow-up. These steps typically involve the presence of a transplant coordinator, physician, social worker, psychologist or psychiatrist, and surgeon. Furthermore, throughout the entire process there is usually a designated living-donor advocate who is experienced in the field of transplantation. The advocate can be a social worker, coordinator, psychologist, psychiatrist, or physician. This advocate should advise the donor independent from recipient interests. ${ }^{2}$

\section{Assessment of the living donor}

The process for determining donor acceptability may vary between transplant programs. According to guidelines outlined by the MultiOrgan Transplant Program of the University Health Network (UHN) in Toronto, separate health care teams assess potential living donors and recipients. Ideally, this would include each donor and recipient with his/ her own physician, coordinator, social workers, and psychiatry staff. This is done to avoid potential conflict of interests. The criteria for assessment include low medical/surgical risk, ability to give informed consent, realistic expectations of donation, voluntary motivation, and sufficiency of economic, practical, and emotional resources to cope with the donation process. ${ }^{17}$ The assessment process includes a full physical evaluation to ensure that the donor is healthy and that there are no major risk factors that would lead to renal disease in the future. The donor is also evaluated for psychological and social barriers to donation. ${ }^{2}$ This process requires involvement from all members of the multidisciplinary team. Similar processes exist across Canada within other multi-organ transplant centres. 


\section{INTERDISCIPLINARY}

In the case of a dispute within the transplantation team about the suitability of a potential donor, the team may review the criteria used to measure suitability. Additional sources of input may include advice from other professional members of the staff, hospital ethics services, legal counsel, hospital administrative resources, or outside hospital consultation. ${ }^{17}$

\section{Informed consent}

Informed consent involves confirming the patient's capacity to understand and consent, disclosing information about the proposed procedure, and ensuring voluntariness. In the context of organ donation this involves a detailed discussion of the risks and benefits to the living donor and recipient. The potential donor should be informed about alternative treatment options for the recipient as well as the possible impact of donation on the donor's lifestyle, family relationships, finances, future employment, and ability to receive life insurance. Donor and recipient are typically provided with general information and details on programspecific outcomes. ${ }^{17}$

When a donor appears undecided, counselling can be offered by a social worker or psychiatrist to assist the potential donor to solve problems and address psychosocial aspects of this decision such as emotional issues and how to inform others. Potential donors should be informed that they can withdraw from the process of donation at any time with the full support of the transplantation team. A crucial part of the assessment process is to ensure that the donor is making his or her decision free from coercive or manipulative influences. ${ }^{17}$

\section{Follow-up}

It is important to evaluate donor and recipient experiences including medical, psychosocial and economic outcomes. According to UHN guidelines, early and late morbidity, graft function, mortality rates and measures of recipient and donor satisfaction are documented in an annual review. In the event that a donor requires further care, appropriate care is arranged..$^{17}$

\section{THE IMPORTANCE OF THE INTERDISCIPLINARY TEAM}

As outlined by the previous section, the interdisciplinary team plays a crucial role in every step of the donation process. In addition, there has been a growing body of evidence showing the benefit of interdisciplinary involvement on quality of patient care (both donor and recipient), patient satisfaction and survival. In particular, a paper by Winsett and Hathaway identified three areas of intervention that will increase the patient's quality of life post-transplant: post-transplant adverse events, employment, and social support. ${ }^{11}$ Literature has shown interdisciplinary teams have been beneficial for providing support for the patient and their family pre- and post-transplant. At the Queen Elizabeth II Health Sciences Centre in Halifax, it was shown that a multidisciplinary kidney disease clinic consisting of nephrologists, nurse educators and dietitians was able to improve metabolic and blood pressure control, and facilitate the use of peritoneal dialysis in late referrals for patients with chronic kidney disease. ${ }^{12}$ In a study by Fonouni, Golriz, Mehrabi, et al., an interdisciplinary team consisting of a transplant surgeon, a nephrologist, a pediatrician, a radiologist, a psychologist, a transplant coordinator, and a transplant nurse was shown to have improved staff communication, patient outcomes and satisfaction with the hospital stay. ${ }^{13}$ Several studies also showed an increase in favourable mental and physical outcomes post-transplant with the involvement of an interdisciplinary team. ${ }^{14,15,16}$

\section{CONCLUSION}

The increasing prevalence of end stage renal disease and the shortage of cadaveric kidneys underline the growing importance of living kidney donation. However, living kidney donation is a complex process that merits careful ethical consideration. This process involves collaboration between multiple health care professions on the side of the donor and the recipient. Health care workers should have an understanding of different aspects of support that are involved in kidney donation in order to inform others and alleviate anxiety surrounding kidney donation. Several studies have already demonstrated that the current shift towards a more integrated and multidisciplinary approach in kidney transplantation improves patient care, satisfaction, and survival. Therefore it should be made clear that the preparation and ultimate outcome of kidney transplantation does not depend solely on the efforts of a nephrologist or transplant surgeon, but rather a team effort.

\section{REFERENCES}

1. Canadian Institute for Health Information. Canadian Organ Replacement Register Annual Report. 2011 Jan [cited 2012 Dec 7];[140 p.]. Available from: https://secure.cihi.ca/free_products/2011_CORR_Annual_Report final e.pdf

2. Davis CL, Delmonico FL. Living-donor kidney transplantation: a review of current practices for the live donor. Nephrol Dial Transplant. 1998 Jul;13(7):1799-803.

3. Terasaki PI, Cecka JM, Gjertson DW, Takemoto S. High survival rates of kidney transplants from spousal and living unrelated donors. N Engl J Med. 1995 Aug 10;333(6):333-6.

4. Asderakis A, Augustine T, Dyer P, Short C, Campbell B, Parrott NR, Johnson RW. Pre-emptive kidney transplantation: the attractive alternative. Nephrol Dial Transplant. 1998 Jul;13(7):1799-803.

5. Roozbeh J, Mehdizadeh AR, Izadfar MA, Razmkon A, Salahi H, Malek-Hosseini SA. Comparison of spousal with other donor groups: Study of a single center. Transplant Proc. 2006 Mar;38(2):562-3.

6. Meier-Kriesche HU, Kaplan B. Waiting time on dialysis as the strongest modifiable risk factor for renal transplant outcomes: a paired donor kidney analysis. Transplantation 2002; 74: 1377-1381.

7. Jimenez M, Living donors help strangers get a second chance. The Globe and Mail 2012 Sept 6;

8. Gentry SE, Montgomery RA, Segev DL. Kidney paired donation: fundamentals,

9. limitations, and expansions. Am J Kidney Dis. 2011 Jan;57(1):144-51.

10. Cecka JM, Significance of histocompatibility in organ transplantation. Current Opinion in Organ Transplantation 2007; 12(4):402-408.

11. Mulley WR, Kanellis J. Understanding crossmatch testing in organ transplantation: A case-based guide for the general nephrologist. Nephrology (Carlton). $2011 \mathrm{Feb} ; 16(2): 125-33$.

12. Winsett RP, Hathaway DK. Predictors of QoL in renal transplant recipients: bridging the gap between research and clinical practice. Posttransplant Quality of Life Intervention Study Group. ANNA J. 1999 Apr;26(2):235-40.

13. Thanamayooran S, Rose C, Hirsch DJ. Effectiveness of a multidisciplinary kidney disease clinic in achieving treatment guideline targets. Nephrol Dial Transplant. 2005 Nov;20(11):2385-93.

14. Fonouni H, Golriz M, Mehrabi A, Oweira H, Schmied BM, Müller SA, Jarahian P, Tahmasbi Rad M, Esmaeilzadeh M, Tönshoff B, Weitz J, Büchler MW, Zeier M, Schmidt J. The role of an interdisciplinary transplant team on living donation kidney transplantation program. Transplant Proc. 2010 JanFeb;42(1):137-40

15. Ehlers SL, Rodrigue JR, Patton PR, Lloyd-Turner J, Kaplan B, Howard RJ. Treating tobacco use and dependence in kidney transplant recipients: development and implementation of a program. Prog Transplant. 2006 Mar;16(1):33-7.

16. Porter GA. Renal rehabilitation: effecting improvement through the team approach. Nephrology 1997;3(3):221-9.

17. Martin JE, Zavala EY. The expanding role of the transplant pharmacist in the 
multidisciplinary practice of transplantation. Clin Transplant. 2004;18 Suppl 12:50-4.

18. Wright, L., Faith, K., Richardson, R., Grant, D., \& Joint Centre for Bioethics, University of Toronto, Toronto, Ont. (2004). Ethical guidelines for the evaluation of living organ donors. Canadian Journal of Surgery.Journal Canadien De Chirurgie, 47(6), 408-413.

\section{MEDICALMART ${ }^{\oplus}$ Your Partner in Health Care Since 1978}

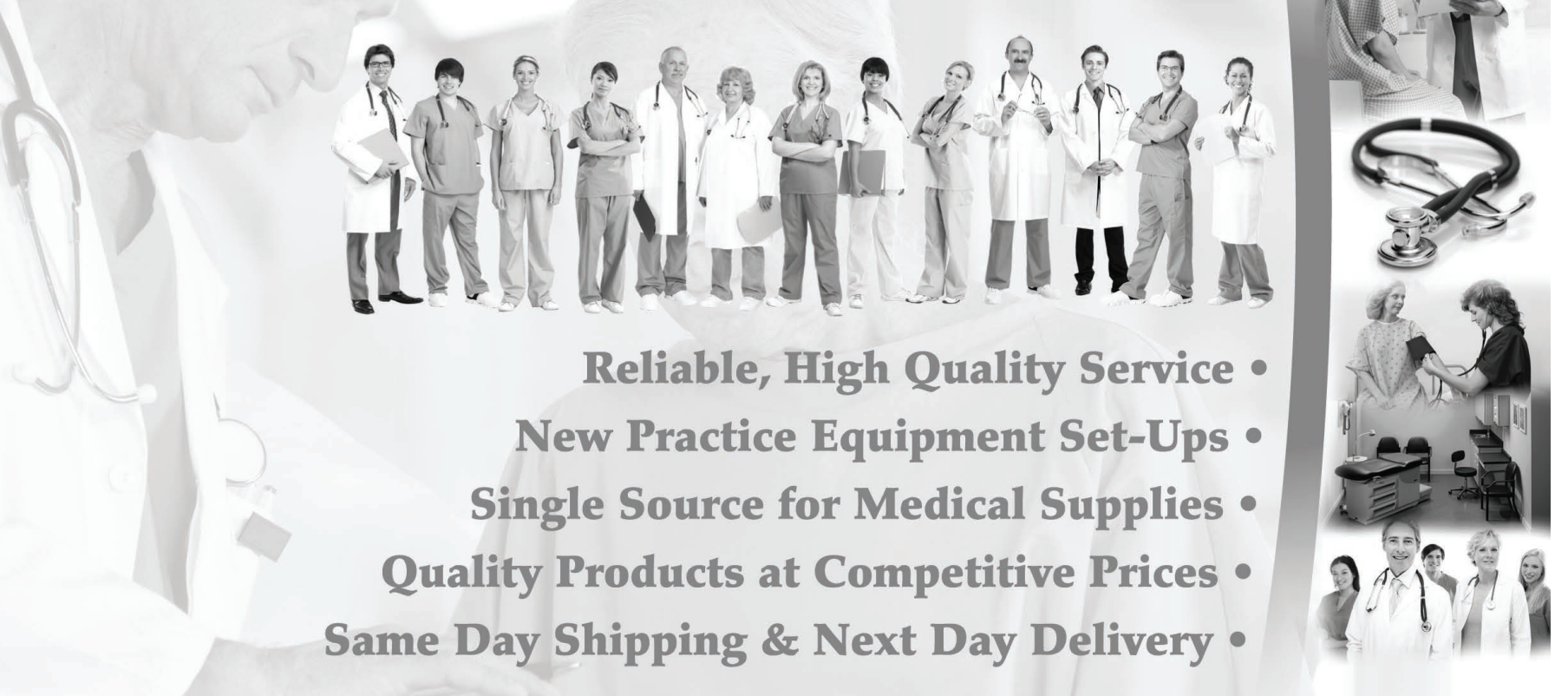

